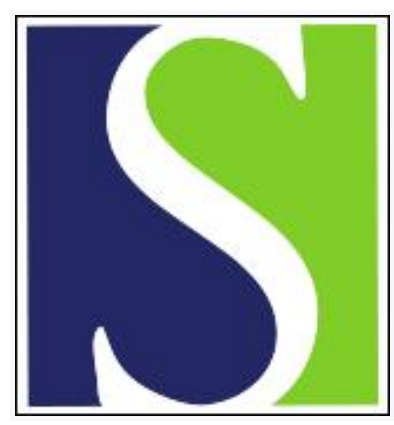

Scand J Work Environ Health 1989;15(1):47-53

https://doi.org/10.5271/sjweh.1882

Issue date: Feb 1989

\title{
Triazine herbicides and ovarian epithelial neoplasms.
}

by Donna A, Crosignani P, Robutti F, Betta PG, Bocca R, Mariani N, Ferrario F, Fissi R, Berrino F

Affiliation: Department of Pathology, City Hospital-USSL, Alesandria, Italy.

This article in PubMed: www.ncbi.nlm.nih.gov/pubmed/2922589

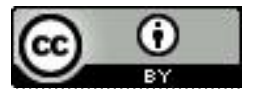




\title{
Triazine herbicides and ovarian epithelial neoplasms
}

\author{
by Adalberto Donna, PhD, ${ }^{1}$ Paolo Crosignani, DSc,MD, ${ }^{2}$ Flavio Robutti, MD, ${ }^{1}$ \\ Pier Giacomo Betta, MD, ${ }^{1}$ Rosanna Bocca, DSc, ${ }^{1}$ Narciso Mariani, MD, ${ }^{1}$ \\ Filippo Ferrario, DSc, $\mathrm{t}^{2}$ Rosaria Fissi, $\mathrm{BA},{ }^{2}$ Franco Berrino, $\mathrm{MD}^{2}$
}

This article is dedicated to the memory of Dr Filippo Ferrario

\begin{abstract}
DONNA A, CROSIGNANI P, ROBUTTI F, BETTA PG, BOCCA R, MARIANI N, FERRARIO F, FISSI R, BERRINO F. Triazine herbicides and ovarian epithelial neoplasms. Scand $J$ Work Environ Health 1989;15:47-53. The possible role of a class of herbicides, triazines, in ovarian carcinogenesis has been evaluated in a population-based case-referent study. The trade names reported by the study subjects, and the type of cultivation in which they worked, were used for the assessment of exposure. Women previously exposed to triazines showed a significant relative risk of 2.7 for ovarian neoplasms. Although none of the doses could be quantified for the study subjects, two risk trends in favor of the plausibility of the association were found: the first by duration and the second by probability of exposure. The population representativity of the study and the comparability of information between the cases and referents suggest the lack of any major bias in the results. Triazine-related risk remained consistent when the analysis was restricted to farmers and when the exposure to other herbicides and to other types of cultivation were considered. Unexposed farmers had the same risk as unexposed nonfarmers.
\end{abstract}

Key terms: agriculture, atrazine, case-referent study, population-based study, reproductive factors, simazine.

Triazines are a class of chemicals widely used as herbicides for the control of germinating weeds in corn (zea mays), and for the control of grass under young forest trees and vines (1).

A possible role in ovarian carcinogenesis has been suggested for triazines in a hospital-based case-referent study carried out by us in 1984 (2). Although the study was inadequate to assess the risk for a specific herbicide, exposure to triazines was often reported by the interviewed subjects. Triazines were also the most used herbicides in the area under study. In 1970 the National Institute of Statistics (3) reported that $51417 \mathrm{~kg}$ of atrazine and $5652 \mathrm{~kg}$ of simazine were sold in Alessandria Province, and it is known that these figures represent only a portion of all sales.

To evaluate the specific role of triazines in ovarian carcinogenesis with a different case series at the population level, a new case-referent study has been conducted in Alessandria (Piedmont, Italy) Province. This investigation was planned to have an $80 \%$ power of detecting a threefold risk with a $5 \%$ significance level (4) on the basis of the risk ratios and the prevalence of exposure found in our previous work.

\footnotetext{
1 Department of Pathology, City Hospital-USSL 70, Alessandria, Italy.

2 Epidemiology Unit, National Cancer Institute, Milano, Italy.
}

Reprint requests to: Dr A Donna, Servizio di Anatomia Patologica, USSL 70, Via Venezia, 18, 1-15100 Alessandria, Italy.

\section{Subjects and methods}

\section{Study base}

In the Alessandria Province, triazines are mainly used as herbicides in corn cultivation. The study was therefore confined to the provincial area where corn is grown, ie, to 143 neighboring municipalities of the 190 municipalities forming the Alessandria Province.

The study base, ie, the "population experience captured" by the study (5), was defined as all women who were at risk of ovarian cancer (ie, had one or both ovaries), were in the age range of $20-69$ years, and were residents in the municipalities under study in the period 1 July 1980 to 30 June 1985 . This period followed the incidence period of the previous study (2).

Women aged 70 years and older were excluded because of the difficulties in tracing and interviewing elderly people and because the histological verification of ovarian tumors is frequently lacking among elderly people (6). Subjects under 20 years of age were also excluded since ovarian epithelial neoplasms rarely occur before that age (6).

\section{Cases and referents}

All women histologically confirmed to have primary malignant epithelial tumors of the ovary [as defined by category I of the World Health Organization (common "epithelial" tumors, ie, serous, mucinous, endometrioid, clear cell, Brenner tumors, mixed epithelial and unclassified epithelial) (7)] newly diagnosed during the study period (1 July 1980 - 30 June 1985) were eligible as cases. The cases were retrospectively identified at the end of the study period from the Alessan- 
dria Hospital Cancer Register, which contains reports from eight hospitals in the Province, and from the archives of 10 other hospitals to which residents in the study area, according to an ad hoc survey (8), were likely to be referred for ovarian cancer.

After the case search was completed, two referents with the same age (plus or minus five years) were randomly selected per case from the electoral rolls of the municipalities of the study area. Those referents who revealed in the interview that they had had a bilateral oophorectomy prior to the study period were excluded from the analysis.

Table 1 shows the distribution of the cases and referents according to their inclusion in the study. Of the 69 eligible cases, 42 were alive and interviewed personally, and 27 were dead at the time of the interview. For 23 of the decedents a close relative could be traced and was interviewed. The mean interval between the diagnosis and the interview was 30 months.

Of the 150 referents selected from the electoral rolls, 13 could not be interviewed, and 11 were excluded because they had undergone a bilateral oophorectomy prior to the study period. The analysis was eventually carried out with data on 65 cases and 126 referents.

Four nonepithelial cases and two cases that were eventually recognized as nonresidents of the study area were excluded, but their referents were nonetheless retained in the referent group. This occurrence accounts for the discrepancy between the numbers of eligible cases $(\mathrm{N}=69)$ and selected referents $(\mathrm{N}=150)$.

\section{Data collection}

A questionnaire was designed to obtain information on reproductive factors, including those reported in the literature $(9,10,11)$ as determinants of ovarian cancer, and to establish occupational exposure to tri-

Table 1. Distribution of the cases and referents according to inclusion in the study.

\begin{tabular}{lrc}
\hline & Number & $\begin{array}{c}\text { Median } \\
\text { age } \\
\text { (years) }\end{array}$ \\
\cline { 2 - 3 } $\begin{array}{l}\text { Cases eligible for the study } \\
\text { Alive and interviewed }\end{array}$ & 69 & 57 \\
Deceased & 42 & 51 \\
$\quad$ Relatives interviewed & 23 & 62 \\
$\quad$ Relatives not traced & 4 & 68 \\
Included in the analysis & & 56 \\
Referents & 65 & 58 \\
Refusals & 150 & 62 \\
Not traced & 4 & 60 \\
Physical or psychological & 6 & \\
impossibility to answer & & 58 \\
Interviewed & 137 & 57 \\
$\quad$ With bilateral oophorectomy & & \\
$\quad$ prior to 1980 & 11 & 47 \\
$\quad$ Included in the analysis & 126 & 56 \\
\hline
\end{tabular}

a $94 \%$ of the eligible cases.

b $91 \%$ of the original referents. azines. There were also questions about the subject's residence and gynecological and other relevant diseases.

A lifelong occupational history of the subject was also requested, and, if any involvement with agriculture was reported, the period and type of cultivation were asked. For each type of cultivation present in the study area, a specific form with a detailed description of tasks and, when applicable, use of herbicides was used.

A list of herbicide trade names was prepared to help subject recall, but it was presented only when a subject was unable to remember the substances she used. Information obtained with the aid of this list was recorded separately.

A final question was asked regarding other nonprofessional instances of exposure to herbicides, ie, any use for domestic purposes, eg, courtyard or garden.

All interviews were held at the subjects' homes. For the deceased cases, the relatives were interviewed. All interviews were conducted by the same person, who was unaware of the disease status prior to, and sometimes even after, the completion of the interview. (In Italy cancer patients are frequently told that they have a benign disease.)

\section{Exposure}

Triazine herbicides are stable chemicals (12), and the mechanisms of human absorption are unknown. It seemed thus reasonable to consider both the preparation and distribution of such herbicides, usually occurring once or twice a year, and the work in the fields where they were used as instances of exposure.

The categories (i) definitely exposed, (ii) possibly exposed, and (iii) unexposed were adopted for exposure to triazines. Subjects who were involved in the preparation or use of triazine herbicides or who worked in corn cultivation with reported use of herbicides were considered definitely exposed. According to local agricultural experts, triazines are in fact used in all herbicide-treated corn cultivation. The possibly exposed subjects were those who acknowledged personal exposure to herbicides, or work in some job possibly involving herbicide exposure, but for whom the substances could not be more precisely identified and those who denied personal usage of herbicides but worked in corn cultivation after 1964, when the use of triazine herbicides on corn crops became extensive in the Alessandria Province, as reported by the National Institute of Statistics (3). The unexposed subjects were those for whom professional or domestic exposure to herbicides could be reasonably ruled out.

Exposure to triazines was established blindly by two of us independently after all the interviews were completed. Only exposure prior to the study period was considered. The length of exposure was defined as the duration, in years, of the occupations involving exposure. Any subject judged as definitely and possibly 
exposed in different periods was classified as definitely exposed. In such cases the length of exposure was computed for the definitely exposed periods only. A summary of herbicide exposure of the definitely exposed subjects is given in the appendix.

\section{Analysis}

Unconditional logistic analysis yielded estimates (13) of the risk ratio (RR), and the associated $90 \%$ confidence interval $(90 \% \mathrm{CI})$ was obtained (4). All variables but age, considered as such, were included in the logistic regression as categorical. The categories used are those reported in the tables. For triazine-related risks, nonexposure was always used as the reference category. We tested the trend of the RR estimates among the categories of exposure by considering the significance of the regression coefficient (4).

\section{Results}

\section{Reproductive factors}

The RR estimates for the reproductive factors are reported in table 2. Parity appeared as a protective factor, and the magnitude of such protection depended on the number of live births, the RR estimate being $0.4(90 \%$ CI $0.2-0.8)$ for the women who had had one to three children and $0.3(90 \% \mathrm{CI} 0.1-1.1)$ for those who had had four or more children. The onetailed P-value for trend was 0.01 when the preceding categories were used.

The users, versus nonusers, of oral contraceptives had an RR estimate of $0.6,(90 \%$ CI $0.2-1.5)$ when age and parity were adjusted for.
Women with menarche prior to the age of 13 years had a risk of $1.1(90 \% \mathrm{CI} 0.6-2.0)$. For those who reported difficulties in conceiving, the risk ratio was $1.7(90 \% \mathrm{Cl} 0.7-3.9)$. Those who miscarried had a risk ratio of 1.4 (90\% CI 0.7-2.8), and for those who had abortions the risk ratio was $0.8(90 \% \mathrm{CI} 0.1-$ 5.5).

The significant risk for single women disappeared after adjustment for age, number of live births, and usage of oral contraceptives.

The frequency of menses seems to influence the ovarian cancer risk. The RR estimate was $2.2(90 \%$ CI $0.4-11.9)$ for short menstrual cycles $(<22 \mathrm{~d})$ and 0.4 (90\% CI $0.1-1.4)$ for long menstrual cycles (>35 d).

The mean age at menopause, among the subjects who were already in menopause before the study period, was 47.6 years for the cases and 48.3 years for the referents.

Age at first birth did not seem to play any particular role. Among parous women, the adjusted risk for those who had their first child at ages of 25 years or more was 1.0 (90\% CI 0.9-1.1).

\section{Triazine-related risks}

Table 3 shows the ovarian cancer risks for the adopted categories of exposure, adjusted for age, number of live births, and use of oral contraceptives. A significant RR estimate of 2.7 (90\% CI 1.0-6.9) was found for the subjects definitely exposed to triazines. Those possibly exposed had a lower risk (RR $1.8,90 \% \mathrm{CI}$ $0.9-3.5$ ). Among both the definitely exposed and possibly exposed subjects, the risks were related to the du-

Table 2. Distribution of the cases and referents by reproductive factors and related risk ratios.

\begin{tabular}{|c|c|c|c|c|c|c|c|c|}
\hline \multirow{2}{*}{ Factor } & \multirow{2}{*}{$\begin{array}{l}\text { Reference } \\
\text { category }\end{array}$} & \multirow{2}{*}{$\begin{array}{l}\text { Exposure } \\
\text { category }\end{array}$} & \multicolumn{2}{|c|}{ Index subjects ${ }^{a}$} & \multicolumn{4}{|c|}{ Risk ratio ${ }^{b}$} \\
\hline & & & Cases & Referents & & Crude & & djusted $^{\circ}$ \\
\hline \multirow{2}{*}{ Parity } & \multirow{2}{*}{ Nulliparous } & $\begin{array}{l}\text { One to three } \\
\text { live births }\end{array}$ & 40 & 95 & 0.4 & $(0.2-0.8)$ & 0.4 & $(0.2-0.8)$ \\
\hline & & $\begin{array}{l}\text { Four or more } \\
\text { live births }\end{array}$ & 3 & 9 & 0.3 & $(0.10-1.1)$ & 0.3 & $(0.10-1.1)$ \\
\hline $\begin{array}{l}\text { Oral contra- } \\
\text { ceptives }\end{array}$ & Nonusers & Users & 5 & 14 & 0.7 & $(0.3-1.6)$ & 0.6 & $(0.2-1.5)$ \\
\hline Early menarche & $\begin{array}{l}\text { Age at menarche } \\
\geq 13 \text { years }\end{array}$ & $\begin{array}{l}\text { Age at menarche } \\
<13 \text { years }\end{array}$ & 22 & 39 & 1.1 & $(0.7-1.9)$ & 1.1 & $(0.6-2.0)$ \\
\hline $\begin{array}{l}\text { Days between } \\
\text { menses }\end{array}$ & $22-35 d$ & $\begin{array}{l}<22 \mathrm{~d} \\
>35 \mathrm{~d}\end{array}$ & $\begin{array}{l}2 \\
3\end{array}$ & $\begin{array}{r}2 \\
10\end{array}$ & $\begin{array}{l}1.90 \\
0.6\end{array}$ & $\begin{array}{l}(0.4-10.00) \\
(0.2-1.7)\end{array}$ & $\begin{array}{l}2.2 \\
0.4\end{array}$ & $\begin{array}{l}(0.4-11.9) \\
(0.10-1.4)\end{array}$ \\
\hline Marital status & Married & $\begin{array}{l}\text { Single } \\
\text { Widowed }\end{array}$ & $\begin{array}{l}12 \\
10\end{array}$ & $\begin{array}{l}12 \\
22\end{array}$ & $\begin{array}{l}2.1 \\
1.0\end{array}$ & $\begin{array}{l}(1.0-4.5) \\
(0.5-2.0)\end{array}$ & $\begin{array}{l}1.0 \\
0.9\end{array}$ & $\begin{array}{l}(0.4-2.70) \\
(0.5-2.0)\end{array}$ \\
\hline Miscarriages & None & One or more & 10 & 18 & 1.1 & $(0.5-2.2)$ & 1.4 & $(0.7-2.8)$ \\
\hline Abortions & None & One or more & 1 & 3 & 0.7 & $(0.10-4.4)$ & 0.80 & $(0.1-5.5)$ \\
\hline $\begin{array}{l}\text { Difficulties } \\
\text { in conceiving }\end{array}$ & Not reported & Reported & 9 & 9 & 2.1 & $(0.9-4.7)$ & 1.7 & $(0.7-3.9)$ \\
\hline Age at first birthd & $<25$ years & $\geq 25$ years & 18 & 55 & 1.0 & $(0.9-1.1)$ & 1.00 & $(0.9-1.1)$ \\
\hline
\end{tabular}

a Subjects in the "exposed" category; as a whole 65 cases and 126 referents were included in the analysis.

b $90 \%$ confidence intervals in parentheses.

c All models include age, parity, and oral contraceptives.

d Among parous women, ie, 43 cases and 104 referents. 
Table 3. Distribution of the cases and referents by triazine exposure and the related relative risk ratios for ovarian cancer.

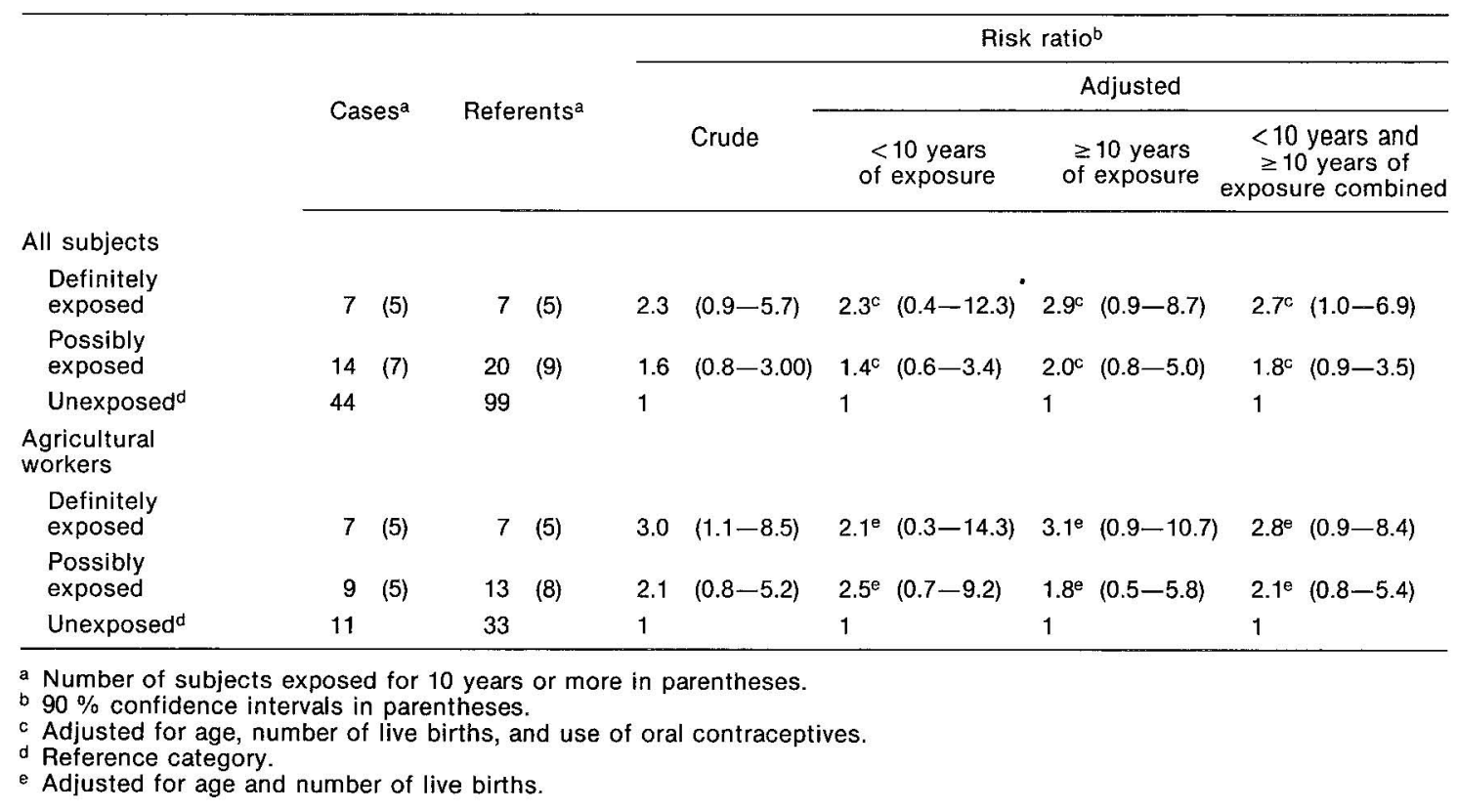

ration of the exposure. The logistic estimate of the regression coefficient for the definitely exposed was $1.7(\mathrm{P}=0.05)$; for the possibly exposed it was 1.4 $(\mathrm{P}=0.08)$.

The risk for the possibly exposed group, being intermediate between the definitely exposed and unexposed groups, is likely to reflect the prevalence of the exposure in the possibly exposed category. In fact, the possibly exposed category was formed from an unknown proportion of triazine-exposed subjects for whom no precise estimate can be made with the use of subject recall.

To evaluate the latency between the exposure and the diagnosis of the disease, we first considered the occupational histories of the definitely exposed subjects. For almost all the subjects with 10 years or more of exposure, triazines began to be used in the early $1960 \mathrm{~s}$ and were still in use in the study period. This study, therefore, does not allow an evaluation of the latency dependence of the observed association.

\section{Discussion}

The study has been designed with the aim of minimizing selection bias by including all incident cases and a representative sample of the study base as referents, controlling any confounding by known risk factors, and avoiding information bias by prior specification for the criteria of gathering and interpreting the information. The extent to which these objectives have been attained are examined in the following discussion.

\section{Population representativity}

We used incidence data from the nearest cancer registry (Lombardy Cancer Registry) (6) to estimate the expected number of cases in the area during the study period, age and age-specific ovarian cancer mortality in the Alessandria province being adjusted for. Seventy-three cases (69 epithelial and 4 nonepithelial) were collected in the study, as against an estimate of 78.19 histologically verified cases. Thus it would seem that only a minority of the cases, if any, might have been lost.

Samples taken from electoral rolls are representative of the source population. Our sampling was, however, carried out at the end of the study period, and interim deaths and migrations from the area were not represented in the file. The expected number of deaths and migrations in the referent group, computed from data of the National Institute of Health, were 5.7 and 0.7 , respectively. Thus, live subjects sampled from the electoral rolls gave a $96 \%$ representativity of the study base.

\section{Reproductive factors}

The estimates for reproductive factors were close to those reported in the literature. This agreement gives indirect evidence in favor of a lack of major biases in the study, although the study size and the prevalence of certain factors do not permit reliable estimates for some determinants.

The age of a woman at the time of her first birth has been proposed as a major etiologic factor for epithelial cancer of the ovary (14). However, in this 
study, as in other studies $(15,16)$, no such association was found.

\section{Data collection}

The data were examined for any difference in the accuracy of the interviews of the cases and referents which might indicate the existence of an information bias. The mean number of recorded periods in the professional history was 2.46 (SD 1.24) for the cases and 2.51 (SD 1.24) for the referents. The mean duration of the interview was $25 \mathrm{~min}$ for both the cases and the referents. For 15 cases and 29 referents another person participated to help subject recall. For two cases and two referents the prepared list of substances was used to help them assess their triazine exposure.

In two instances there was disagreement between the two evaluators in attributing exposure. Both were due to an error in applying the formal exposure criteria, and the correction was straightforward.

Thirty-five percent of the cases were dead at the time of the data collection. Since information obtained from relatives may be less complete and precise, the triazinerelated risk was evaluated separately for the living and dead cases. The crude RR estimate for the deceased subjects was $1.9(90 \% \mathrm{CI} 0.5-7.6)$ for the definitely exposed and $2.0(90 \% \mathrm{CI} 0.8-4.8)$ for the possibly exposed. The corresponding estimates for the living cases were $2.4(90 \% \mathrm{CI} 0.9-6.8)$ and $1.4(90 \% \mathrm{CI}$ $0.5-4.1$ ), respectively. Thus the risk showed lower values than the overall estimate for the definitely exposed decedents and higher values for the possibly exposed decedents. A possible interpretation could be that a slightly higher proportion of definitely exposed subjects was classified as possibly exposed when relatives were interviewed.

\section{Specificity of association and confounding}

To evaluate whether the observed risk for triazine exposure reflected a nonspecific agricultural risk only, we restricted the analysis to those who reported having worked in agriculture, henceforth called "farmers." As shown in table 3, the estimates were slighty higher, and the trends were retained in relation to the duration of exposure among the definitely exposed group, and to the proportion of exposed.

The risk for the unexposed farmers was about the same as that for the unexposed nonfarmers (RR 0.9, $90 \% \mathrm{CI} 0.5-1.9$ ) when adjusted for age, number of live births, and use of oral contraceptives.

The criteria used to establish exposure to triazines were based both on the reported herbicide trade names and on work in corn cultivation. This practice is probably acceptable because, in our study, all trade names reported as herbicides used in corn cultivation were in fact triazines.

A number of farmers used herbicides for crops other than corn, and especially for wheat. Table 4 gives the details of exposure to other herbicides by categories of exposure to triazines. As farmers who use triazines tend also to use other herbicides, exposure to different kinds of herbicides tends to be associated. The data, however, do not suggest any association between exposure to other herbicides and ovarian cancer.

Cultivation of other crops might be an indicator of farmers' exposure to chemicals not considered in the study. Adjustment for other types of cultivation in the area, ie, wheat, vegetables, forage, and vines, produced only minor changes in the risk estimate.

Information on many reproductive factors was collected in this study. Taking into account age, number of live births, and use of oral contraceptives slightly increased the triazine-related risk estimates. When all the reproductive factors listed in table 2 were included in the model, there was virtually no change in the estimates. Confounding by reproductive factors thus does not seem a possible explanation for the estimated risks.

When establishing the study base, as a precaution, we also excluded an area with asbestos pollution, since

Table 4. Farmers' exposure to other herbicides according to triazine exposure.

\begin{tabular}{|c|c|c|c|c|c|c|c|}
\hline \multirow{2}{*}{$\begin{array}{l}\text { Triazine } \\
\text { exposure }\end{array}$} & \multicolumn{5}{|c|}{ Herbicide $^{a}$} & \multirow[b]{2}{*}{ All } & \multirow[b]{2}{*}{ Unexposed } \\
\hline & Chlortoluron & Trifluralin & $\begin{array}{l}\text { Trifluralin } \\
\text { and Linuron }\end{array}$ & Alachlor & $\begin{array}{l}\text { Unknown } \\
\text { on wheat }\end{array}$ & & \\
\hline \multicolumn{8}{|c|}{ Definitely expośed } \\
\hline $\begin{array}{l}\text { Cases } \\
\text { Referents }\end{array}$ & $\begin{array}{l}1 \\
1\end{array}$ & $\overline{2}$ & $\begin{array}{l}1 \\
1^{c}\end{array}$ & $\overline{1}$ & $\underline{3}$ & $\begin{array}{l}5 \\
5\end{array}$ & $\begin{array}{l}2 \\
2\end{array}$ \\
\hline \multicolumn{8}{|c|}{ Possibly exposed } \\
\hline $\begin{array}{l}\text { Cases } \\
\text { Referents }\end{array}$ & $\overline{1}$ & $\overline{-}$ & - & - & $\overline{-}$ & $\overline{1}$ & $\begin{array}{r}9 \\
12\end{array}$ \\
\hline \multicolumn{8}{|l|}{ Unexposed } \\
\hline $\begin{array}{l}\text { Cases } \\
\text { Referents }\end{array}$ & - & $\overline{-}$ & - & $\overline{-}$ & $\overline{2}$ & $\overline{2}$ & $\begin{array}{l}11 \\
31\end{array}$ \\
\hline
\end{tabular}


this substance has been reported as a risk factor for ovarian cancer (17).

\section{Concluding remarks}

The main result of this study was that women with previous exposure to triazine herbicides showed a twoto threefold risk of epithelial ovarian cancer as compared to unexposed women. This finding is consistent with the results of our previous study (2) and alternative explanations seem unlikely.

Although no doses could be quantified among the study subjects, two risk trends in favor of the plausibility of the association are noticeable in the data, ie, one for the duration of exposure and the other for the probability of exposure.

Limited experimental evidence of the carcinogenic effect of triazines on animals (commercial products, given subcutaneously or intraperitoneally to Swiss albino female mice at $2 \mathrm{ppm}$ ) has been reported (18), with a suggestive specific action on mesodermal-derived tissues. As ovarian surface epithelial neoplasms are, in fact, tumors of the ovarian mesothelium (19), we might speculate that this neoplasm is a model for the carcinogenic action of triazines on the mesoderm.

The study results, and possibly the presented arguments, are also supported by the risk of non-Hodgkin's lymphomas associated with triazine exposure, as was recently found by Hoar et al (20) in an epidemiologic study on farmers in the state of Kansas in the United States.

\section{Acknowledgments}

This study was supported by the "Lega Italiana per la Lotta contro i Tumori," Alessandria Province Section, by the Local Health Unit, and by the Italian National Research Council (Progetto Finalizzato Oncologia) under contract no 84.00448.44.

We are indebted to Dr G Caponetto, agricultural expert of Local Health Unit No 70, for his advice on cultivation and herbicides and to Dr R Capocaccia, National Institute of Health, Rome, for his kind supply of mortality and population data regarding the Alessandria Province. We also thank Dr E Merler, Dr P Vineis, and Dr P Comba for their helpful review of the manuscript.

\section{References}

1. The Royal Society of Chemistry. The agrochemical handbook. Nottingham (England): The Royal Society of Chemistry, The University, 1985. (Update 4).

2. Donna A, Betta PG, Robutti F, Crosignani P, Berrino F, Bellingeri D. Ovarian mesothelial tumors and herbicides: a case-control study. Carcinogenesis 1984;5: $941-2$.

3. National Institute of Statistics (ISTAT). Annuario di statistica agraria, 1962-1976. Rome: ISTAT, 19631977.

4. Schlesselman JJ. Case-control studies. New York, New York: Oxford University Press, 1982.

5. Miettinen OS. Theoretical epidemiology. New York, New York: John Wiley and Sons, Inc, 1985:46-56.

6. Berrino F, Crosignani P, Gatta G, Macaluso M, Pisani P, Vigano' C. Varese Province: incidence 1978--1981. In: Cancer incidence in five continents; vol 5. Lyon: International Agency For Research on Cancer (in press).

7. Serov SF, Scully RE. Histological typing of ovarian tumours. Geneva: World Health Organization, 1973.

8. Mariani N. Indagine epidemiologica sui tumori maligni ovarici in Provincia di Alessandria [Doctoral dissertation]. Pavia (Italy): Preventive and Community Medicine Department, University of Pavia, 1985.

9. Cramer DW, Hutchison GB, Welch WR, Scully RE, Ryan KJ. Determinants of ovarian cancer risk: I reproductive experiences and family history. $\mathbf{J}$ Natl Cancer Inst 1983;71:711-21.

10. Greene MH, Clark JW, Blayney DW. The epidemiology of ovarian cancer. Semin Oncol 1984; 1 1:209-26.

11. Heintz APM, Hacker NF, Lagasse LD. Epidemiology and etiology of ovarian cancer: a review. Obstet Gynecol 1985;66:127-35.

12. Geller A. Studies on the degradation of atrazine by bacterial communities enriched from various biotopes. Arch Environ Contam Toxicol 1980;9:289-305.

13. Breslow N, Day NE. Statistical methods in cancer research; vol I (The analysis of case-control studies). Lyon: International Agency for Research on Cancer, 1980. (IARC scientific publications no 32.)

14. La Vecchia C, Decarli A, Franceschi S, Regallo M, Tognoni G. Age at first birth and the risk of epithelial ovarian cancer. J Natl Cancer Inst 1984;73:663-6.

15. Lesher L, McGowan L, Hartge P, Hoover R. Age at first birth and risk of epithelial ovarian cancer [Letter to the editor]. J Natl Cancer Inst 1985;74:1361.

16. Voigt LF, Harlow BL, Weiss NS. The influence of age at first birth and parity on ovarian cancer risk. Am J Epidemiol 1986;124:490-1.

17. Acheson ED, Gardner MJ, Pippard EC, Grime PL. Mortality of two groups of women who manifactured gas masks from chrysotile and crocidolite asbestos: a 40-year follow-up. Br J Ind Med 1982;39:344-8.

18. Donna A, Betta PG, Gagliardi F, Ghiazza GF, Gallareto M, Gabutto V. Preliminary experimental contribution to the study of the possible carcinogenic activity of two herbicides containing atrazine, simazine and trifluralin as active principles. Pathologica 1981;73:707-21.

19. Parmley TH, Woodruff JD. The ovarian mesothelioma. Am J Obstet Gynecol 1974;20:234-41.

20. Hoar SK, Blair A, Holmes FF, Boysen CD, Robel JR, Hoover R, Fraumeni GF. Agricultural herbicide use and risk of lymphoma and soft-tissue sarcoma. JAMA $1986 ; 256: 1141-7$. 


\section{Appendix}

\section{Herbicide exposure of definitely exposed subjects}

\section{Cases}

BB used triazine in vineyards from 1979 to 1980 .

DA used triazine on corn from 1958 to 1983 and also chlortoluron (3-(3-chloro-p-tolyl)-1,1-dimethylurea) (1) on wheat.

MI worked in corn and wheat fields where her husband used herbicides from 1970 to 1980 ; neither the husband nor the subject could recall the trade names of the herbicides used.

PA worked in corn and wheat fields from 1964 to 1986 where the herbicides were spread by other people and the trade names could not be retrieved.

PG worked in corn and wheat fields where her father used herbicides from 1964 to 1984 , but the respondent (the husband) was not aware of the herbicides used.

RM used triazine in corn fields from 1970 to 1981; in the same period she also used trifluralin (2,6-dinitro-N, N-dipropyl-4-trifluoromethylaniline) and linuron (3-(3,4-dichlorophenyl)-1methoxy-1-methylurea (1) in wheat fields.

RR used triazine on corn in 1979.

\section{Referents}

BL used triazine in corn fields and vineyards from 1964 to 1986, and also trifluralin on wheat in the same period.

$\mathrm{BaM}$ used triazine in beet fields and alachlor (2-chloro-2',6'-diethyl-N-(methoxymethyl)acetanilide) (1) on spinach from 1964 to 1986.

$\mathrm{BrM}$ worked from 1966 to 1985 in corn and wheat fields where herbicides were used by her husband.

ME used triazine in corn fields and trifluralin, linuron and MCPA (4-chloro-2-methylphenoxy acetic acid) (1) in wheat fields from 1965 to 1986.

MP used triazine in vineyards in 1979.

NM used triazine in corn fields and chlortoluron in wheat fields from 1964 to 1986.

PV used triazine in vineyards in 1971.

\section{References}

1. The Royal Society of Chemistry. The agrochemical handbook. Nottingham (England): The Royal Society of Chemistry, The University, 1985. (Update 4). 